\title{
L'asymétrie de l'information
}

Que de raisonnements courts!

Un exemple: «La médecine est régie par une asymétrie de l'information. Le médecin sait, la patiente ou le patient ne savent pas. Ce monopole du savoir permet d'exploiter une population démunie.»

Je ne rétorquerai pas ce que vous pensez déjà, par exemple que nous consultons le médecin, parce que, justement, nous espérons qu'il sait pourquoi nous avons les jambes enflées. «ll a fait des études, le Docteur!»

Mon estocade porte ailleurs.

Le coût élevé de la santé est explicable, en partie, par un raisonnement inverse. L'asymétrie de l'information n'est pas là où on croit.

Concentrons-nous!

Le patient en sait beaucoup plus que le médecin au sujet de ce qui lui arrive. Insatisfait par une première réponse, le malade consulte ailleurs, jusqu'à ce qu'il obtienne une réponse qui lui convienne, que ce soit en médecine classique ou complémentaire, sans oublier la divination et les tarots.

Quand le médecin était cru, le malade se le tenait pour dit. Le processus s'arrêtait, ce qui n'était pas idéal.

Maintenant que le praticien fait partie, selon nos autorités, des abuseurs publics, il est normal qu'on s'en méfie. «Il m'a dit que mes chevilles enflaient à cause de mon cœur. Il n'a rien compris!» Et d'aller consulter ailleurs.

A l'évidence, le mouvement va dans les deux sens.

Celui qui offre (le médecin) en sait beaucoup sur la maladie.

Celui qui demande (la patiente ou le patient) en sait beaucoup plus sur sa propre souffrance.

Docteur Claude Aubert Membre du Comité central de la FMH 